\title{
Papel de la teología en el mundo actual
}

\section{Pedro Trigo, Centro Gumilla,}

Caracas.

\section{Introducción: delimitación del tema}

Como el tema es inabarcable, lo desarrollaremos entendiéndolo en sentido estricto, es decir refiriéndonos tan sólo a los énfasis que tendría que tener la teología para responder al mundo en el que vivimos. No nos vamos, pues, a referir a la tarea que tiene la teología de todos los tiempos, aunque, obviamente, será tenida constantemente en cuenta como telón de fondo.

Para decirlo en referencia al Vaticano II (GS 22), toda teología auténtica trata de Dios, o más exactamente, del Dios de Jesús y de su distinción de todo aquello ante lo que los seres humanos nos postramos y rendimos culto, es decir, nos consagramos a ello, sea bajo formas religiosas o no. Pero para los que hemos recibido la revelación judeocristiana, no es posible tratar de Dios sin implicar al ser humano, como, correlativamente, tampoco es posible definir al ser humano, prescindiendo de Dios. Para nosotros los cristianos, tanto Dios como el ser humano han sido revelados conjuntamente por Jesús de Nazaret. La implicación consiste en que, al hacerse hermano nuestro el Hijo único de Dios, nos ha hecho a nosotros, sus hermanos, hijos de Dios, hijos en el Hijo, y por consiguiente, somos también hermanos entre nosotros, hermanos de todos los seres humanos en el Hermano universal. Eso lo proclamamos nosotros como testigos y compañeros, es decir, como miembros del pueblo de Dios, que ha recibido esta revelación y se consagra (y es consagrado por Dios) a que acontezca. Eso es lo que significa que la Iglesia es sacramento universal de salvación o sacramento de la unidad de todo el género humano. Éste es el núcleo de la teología. Pero no trataremos directamente de ello, sino de los énfasis requeridos por el mundo actual.

Entiendo por mundo actual este mundo globalizado, vivido en nuestro caso desde la época en que está entrando América Latina y desde cada país y situa- 
ción, en nuestras respectivas comunidades cristianas, en la Iglesia latinoamericana y universal. Por eso, nuestro estudio tendrá tres partes: la primera, el papel de la teología en el mundo globalizado; la segunda, su función en la nueva época a la que está entrando América Latina; y la tercera, su cometido en una situación que relega lo religioso al ámbito privado y provoca como reacción los fundamentalismos. Los subtítulos señalarán el papel que atribuimos a la teología, en cada uno de los contextos.

\section{Papel de la teología en el mundo globalizado}

En la dirección dominante de esta figura histórica globalizada, marcada por el mercado totalitario, la trascendencia, tanto la humana como la divina, no tienen ningún significado ni lugar; más aún, son positivamente rechazadas, ya que al absolutizar el circuito de producción-consumo, y por tanto, la relación sujetoobjeto, todo lo demás queda relativizado, es decir, en función de ellos, incluido, en primer lugar, el ser humano, pero también la religión y, más en general, la relación sujeto-sujeto.

Así, pues, en la dirección histórica que prevalece, seduciendo y, en definitiva, imponiéndose, la teología sólo puede tener cabida como la versión religiosa del sistema, que lo sacraliza (y es muy requerida en algunos ambientes muy influyentes; el caso más patético es el del presidente de Estados Unidos, que se siente aliado de Dios para luchar contra el eje del mal) o como la teoría de lo que se consume a nivel particular en uno de tantos nichos de la sección de artículos religiosos, en el gran bazar cultural (así se resignan a practicarla no pocos teólogos, que parten del hecho del mercado religioso para promover en él su oferta, razonando sus ventajas).

En esta misma figura histórica sin embargo, se da activamente otra dirección, que, desde la asunción de sus bienes civilizatorios, se encarga de que se realicen con la mayor plenitud posible sus bienes culturales, relegados y aun negados por la dirección dominante, sobre todo la cultura de la democracia, como modo de producción social omniabarcante, y la cultura de los derechos humanos y de la vida, como contenidos medulares.

Éste es el nicho de la teología católica (en el sentido textual y primigenio del término), en nuestro mundo globalizado. La teología de la cultura de la democracia deberá trabajarse como una expresión imprescindible de la fraternidad universal, que propugna el cristianismo. La de los derechos humanos, como una expresión más primaria de la dignidad creatural del ser humano, escatologizada al considerar la creación en miras a la constitución de la familia universal de las hijas e hijos de Dios. La teología de la vida se apoya, más elementalmente aún, en la comunión de todos en el único sistema de sistemas que es el universo y en la sacralidad de la vida. 


\subsection{Fundamentar la sacralidad de la vida}

Que la vida es sagrada no va de suyo en nuestro mundo, como no ha sido de ningún modo evidente a lo largo de la historia. Hoy, se excluye de los bienes civilizatorios y culturales a la mayoría de la humanidad, con lo cual se la condena a vivir de mengua, de enfermedades de pobres y de la frustración que da la sensación de impotencia y de estar como de sobra en este mundo, en el que nadie los toma en cuenta. Hoy, se sobreexplota y humilla a buena parte de la humanidad, a la cual, a la vez que se la exprime, se la priva de derechos fundamentales, sobre todo el de la participación responsable en el diseño y la conducción de la sociedad. Hoy, se unidimensionaliza a los que integran la sociedad de consumo, poniéndolos en función del circuito, cada vez más omniabarcante y acelerado, de la producción y del consumo, y de este modo, se vacían de sustancia humana.

Estos tres fenómenos son masivos, públicos y estructurales. Ellos muestran palmariamente que no se considera a la vida humana como una magnitud absoluta, es decir, que no entra como mero ingrediente de ninguna construcción histórica y que, por tanto, no es un bien transable, en ninguna operación. Si esto decimos de la vida humana, mucho más evidente es la falta de respeto hacia las demás formas de vida y hacia la vida del planeta tierra como tal.

Una teología que se empeñe en asentar el carácter sagrado de la vida y en sacar las consecuencias concretas que de esto se deduce, tiene que enfrentar a los fautores de la dirección dominante de esta figura histórica, a los que insta a relativizar el circuito producción-consumo, para ponerlo en función de la vida. Esto implica reordenarlo todo. Una teología responsable es objetivamente contradictoria respecto de la dirección dominante de esta figura histórica, y esta cruz ha de ser llevada, incluso para el bien de sus contradictores, queridos como seres vivos, compañeros en el único barco de la vida, en el cual todo está interconectado y en el cual no es posible salvarse del conjunto.

Es crucial que esta teología se presente no como el otro polo del mismo horizonte (por ejemplo, la discusión anglosajona entre liberales y comunitaristas), sino que se sitúe en el horizonte alternativo de la vida sagrada en el que queden afirmados los bienes civilizatorios actuales y en el que tengan lugar, reintegrados a su humanidad y a la humanidad y, por tanto, trascendidos, los que los usufructúan.

Esta teología tendrá que mostrar a Dios como el que mantiene la creación ante sí como independiente de sí, respetándola en su verdad, ya que la ha creado con sentido, porque ha sido creada por la Palabra, y alentándola con el soplo trascendente de su Espíritu. Más aún, tiene que mostrar a Dios comprometiéndose con su creación, como el Dios de la alianza, empezando por la alianza con Noé, alianza con todos los seres vivos, pastoreados por el ser humano (Gn 9, 1-17). O, dicho en clave sapiencial, tiene que presentar a Dios como el amigo de la vida (Sab 11, 26). 


\subsection{Dar razón de la especial sacralidad del ser humano}

Esta teología tiene que mostrar la especial dignidad del ser humano, en el conjunto de la creación; más aún, su relativa externidad respecto de todo lo creado, ya que su ser no se agota en su pertenencia a la tierra, porque ha sido creado capaz de Dios, es decir, capaz de recibir su libre comunicación personal y de corresponderla o, si no, de estar ante el silencio del Eterno. Por eso, el ser humano no se agota y ni siquiera se define como parte de ningún conjunto natural, ni histórico, aunque pertenezca a muchos de ellos. En eso consiste su sacralidad, incomparablemente superior a la del resto de los seres vivos. Él está aparte de cualquier cálculo. Él como persona no es una magnitud que entre a formar parte de ningún conjunto de magnitudes. Él como tal, es decir cada ser humano como humano, debe ser considerado aparte, valorado por sí mismo de manera absoluta. Por eso, no puede ser considerado como el costo social de una empresa económica o política. No pueden ser sacrificados seres humanos para aumentar la tasa de ganancia o para que se mantenga un orden social o para alcanzar una meta política.

Si el ser humano asume este estatuto, está en condiciones de cumplir el encargo divino de cuidar de la tierra, llevándola a su plenitud y a él en ella. Esta perspectiva excluye la consideración de la tierra como una mera cantera para explotar hasta que sea posible. La consideración de la tierra como un sistema de sistemas es la única que permite el desarrollo sustentable. Una teología responsable tiene que hacer ver la irracionalidad del modo actual de explotación de los recursos, tanto los renovables como los no renovables.

Pero también deberá hacer ver la conexión entre la falta de respeto a la tierra y la falta primordial de respeto a sí mismo. Asumiendo como punto de partida actual al individuo, hay que hacer ver no sólo que no se respeta a la tierra, porque no se respeta a los seres humanos, sino que no se los respeta porque tampoco uno se respeta a sí mismo. Es decir que, si es verdad que el indicio de que no me respeto como ser humano es que no respeto a los demás, la causa de no respetarlos es que tampoco me respeto a mí.

El problema actual de los derechos humanos, que consiste en la falta de reconocimiento del derecho que tiene todo ser humano a que se lo respete positivamente, es decir, no sólo a que no se interfiera en su vida, sino a que se la facilite en intercambio simbiótico, y eso como un deber respecto de los demás, está anclado en la falta de reconocimiento de los deberes que cada uno tiene consigo mismo y en el derecho que tiene su ser de que se lo trate como un ser sagrado y no se lo use, como si fuera un instrumento, para satisfacer el deseo absolutizado de una parte de su ser que se autonomiza del conjunto. Para que la teología actual cumpla su función hoy, es indispensable que haga ver esta correlación para que la insistencia en la obligación hacia los derechos humanos de los demás 
no sea percibida como algo externo a la propia persona, incluso como algo que coerce su desarrollo.

Hoy, al estar todos en presencia de todos, es más fácil comprobar si lo que se proclama como derechos humanos lo son en verdad o en realidad se restringen a derechos de los asociados, de los ciudadanos, de los de la propia cultura. Por eso, la señal de que se respetan los derechos humanos es que se respetan los derechos de los otros, es decir, de los de otras culturas tenidas como inferiores que conviven como inmigrantes en la misma área, y que los ciudadanos y las empresas de esos países desarrollados respetan a los del tercer mundo, en el tercer mundo.

Los simplemente otros, los otros sin cualificación, son en todas las culturas los pobres, que son más pobres todavía si son los pobres de las culturas tenidas como atrasadas y carentes de empuje histórico. Por tanto, la señal absoluta de que se respetan los derechos humanos es que se respetan los derechos de los pobres, porque ellos son los que, injustamente, son tenidos como sin atributos o sin más atributos que el de ser seres humanos.

Si Dios respeta absolutamente a cada ser humano, de tal manera que todo lo que crea o inspira, desde los mandamientos hasta las religiones son para el ser humano y no él para ellos, también cada ser humano debe respetarse a sí mismo y a los demás. Y el culmen del respeto a sí mismo es disponerse a recibir la relación personal de Dios, viviendo estructuralmente abierto a ella.

El respeto absoluto que tiene Dios a cada ser humano reluce en el respeto que tiene al pobre, a quien por serlo, no le son reconocidos sus derechos. Por eso, se puede concluir que la prueba más clara de que alguien se respeta a sí mismo es que respeta al pobre. Esto vale también obviamente para los propios pobres. El respeto al pobre es también la señal más contundente de que se corresponde a la relación de Dios, ya que uno hace con el pobre el equivalente finito de lo que Dios hace con uno. Esto mismo habría que afirmarlo con particular énfasis de la relación con Jesús. En palabras de Aparecida: "Todo lo que tenga que ver con Cristo, tiene que ver con los pobres y todo lo relacionado con los pobres reclama a Jesucristo" (257).

\subsection{Mostrar cómo la sacralidad humana se decanta positivamente como fraternidad universal}

La fraternidad universal es trascendente, respecto de la solidaridad derivada de ir todos en el mismo barco, de pertenecer todos al mismo sistema de sistemas que es la tierra; incluso trasciende al hecho de que como seres humanos, vivimos vertidos los unos en los otros, somos respectivos de cada ser humano y de la humanidad como un todo, y al aceptar este hecho ponemos en común nuestros haberes para constituir cuerpos sociales. Es verdad que todo esto va mucho más 
allá de lo que hacen los que están configurados por la dirección dominante de esta figura histórica y que hay que luchar denodadamente para que se enderece el rumbo y se transite en esa dirección. Incluso tenemos que afirmar que todo esto es una exigencia de la fraternidad humana, que propugna el cristianismo. Pero esta fraternidad universal va mucho más allá.

Decimos que es trascendente porque no hay nada en lo que es constitutivamente el ser humano que la exija. Pertenecer todos a la misma especie da para ayudarnos como miembros del mismo conjunto. Es una actitud no sólo de realismo, sino de hacer justicia a la realidad. Por tanto, es una actitud que nos humaniza. Pero eso, no equivale a ser hermanos. Sólo pueden llamarse con propiedad hermanos quienes derivan de los mismos progenitores. Claro está que en una concepción monogenista, en definitiva, todos salimos del mismo tronco, simbólicamente de Adán y Eva. Pero descendientes del mismo tronco no es lo mismo que hermanos. Podemos decir, y esto ya es bastante, que tenemos un aire de familia. Pero la historia humana no tiene, como pensaban los autores bíblicos, menos de seis mil años en tiempos de Cristo, sino que supera tal vez el millón de años, por lo que las diferenciaciones cobran tanto peso o mucho mayor que la proveniencia común.

Los cristianos afirmamos que Dios no es sólo nuestro creador, es decir, el que nos da nuestro ser, sino también nuestro Padre-Madre, porque nos da su ser, es decir, porque en Jesús, su Hijo único, nos ha hecho sus hijos, es decir, nos ha hecho partícipes de aquello que a él lo constituye Padre-Madre. Eso ha acontecido en dos fases. En primer lugar, Jesús se ha hecho nuestro Hermano, cargando con toda la humanidad. Es el mesianismo asuntivo del Siervo, que se revela en el bautismo y se historiza a lo largo de su vida, que culmina en la cruz. Así, somos hijos en el Hijo. Pero también, al morir-resucitar (Jn 19, 30), nos ha entregado a su Espíritu de Hijo, que nos mueve desde más adentro que lo íntimo nuestro. Por eso, si aceptamos dejarnos mover por él, es decir, si nos dejamos llevar por el espíritu de hijos, somos verdaderos hijos de Dios.

Creemos que en esta época de mundialización, la fraternidad es el alma de la humanidad una, que sin esta alma se empantana, en la lucha de todos contra todos para que prevalezcan los mejor posicionados, más audaces y con menos escrúpulos. Eso es lo que significa para el Vaticano II que la Iglesia es sacramento de la íntima unión a la que por designio de Dios se encamina el género humano.

Afirmábamos al comienzo que la cultura de la democracia es una expresión muy actual y muy profunda de la fraternidad universal. Éstas serían sus características. El primer paso que debe dar cada uno de los integrantes del grupo es poner en común los propios haberes, no reservarlos como una ventaja sobre los demás. El segundo paso es escuchar lo que dicen los otros, que exige salir del propio horizonte y abrirse a la perspectiva de los demás. El tercer paso consiste en dialogar sobre lo dicho por cada uno, intentando aclarar lo que no se ve o ma- 
nifestando lo que no se comparte. El cuarto paso es buscar una toma de posición o una propuesta que sean del grupo: es el paso de cada yo al nosotros. El quinto paso es encargarse cada quien de un aspecto de lo decidido: es el ejercicio de la responsabilidad asumida. El sexto paso es la evaluación conjunta: es la muestra más fehaciente de que todos somos sujetos y que se comparte la responsabilidad. El séptimo paso es el procesamiento de conflictos de manera que el grupo salga fortalecido como cuerpo social personalizado. El octavo paso es la celebración de los logros y, más en general, de la vida compartida: es un momento privilegiado de comunión personalizadora.

Como se ve, el cultivo de la cultura de la democracia, en todos los ámbitos de la vida, desde la familia a la escuela, a los grupos de interés, a la vida ciudadana, hasta llegar a la política y la economía, las instancias más refractarias, es un ejercicio muy exigente y fecundo, que se debe cultivar asiduamente, desde el fondo del corazón. Quien se tome en serio cada uno de los pasos, convendrá en que esta práctica entraña una verdadera salida de sí, una verdadera trascendencia. Toca a la teología mostrar cómo la cultura de la democracia es expresión actual sobresaliente de la aceptación y la práctica del reinado de Dios que nos reveló e hizo presente Jesús.

\subsection{Desmontar el fetichismo del totalitarismo de mercado devolviéndolo a la fluidez de la historia}

Si eso es lo que hay que hacer, tampoco hay que omitir la valoración teológica de la dirección dominante de esta figura histórica, porque su prestancia es tal que nos presiona con gran fuerza, también nos seduce y de todos modos configura el menú de posibilidades y limitaciones que nos ofrece esta época, que no son, obviamente, las únicas, pero sí las que más están a la mano.

Una función ineludible de la teología es, pues, desmontar el sistema fetichista imperante. Para eso tiene, en primer lugar, que poner al descubierto la entraña fetichista del mercado corporativizado y absolutizado, que vive de víctimas. Éste, para encubrirse, segrega una matriz de opinión que enfatiza de tal modo la complejidad inabarcable de los actores y las variables que están en juego y el hecho de la causalidad múltiple y en muchos casos recíproca, que concluye de ella que cada actor debe atenerse a lo que directamente hace y que sólo de ello es responsable; lo demás son efectos colaterales, difícilmente demostrables, o en todo caso, costos no pretendidos de todo proyecto, que no pueden pretender paralizarlo. Este estado de opinión obliga a la teología a abandonar posturas ideologizadas, en las que todos somos proclives a caer por la exasperación que provoca la situación de pecado, y abocarse a desentrañar pacientemente la realidad.

Este afán de realidad y esta actitud de honradez con ella son direcciones irrenunciables de la teología cristiana, ya que es la relación de nuestro Dios con nosotros y con todos los vivientes la que nos hace reales. Ahora bien, realidad 
no es lo mismo que orden establecido, ya que todos los órdenes sociales que conocemos en la historia han distorsionado, más o menos, la realidad, y no pocos, como el actual, la han violentado terriblemente. Es lo que expresa Pablo con inusitada dureza: "se revela la ira de Dios contra toda clase de seres humanos impíos e injustos, que con su injusticia esconden la verdad" $(\mathrm{Rm} 1,18)$.

Pero el trabajo de descubrir la realidad que ocultan la propaganda, los estados difusos de opinión, las reglas de juego internalizadas, la mentalidad y la sensibilidad dominantes, debe hacerse de tal modo que el teólogo y su teología no queden hipnotizados por el fetiche, porque blasfemar de él significa considerarlo divino, tanto como postrarse ante él obsecuentemente.

Para que sea católica, esta teología tendrá como objetivo reconducir lo fetichizado a la fluidez de la historia, en la cual se hace justicia a lo que tiene de bueno y se pone en guardia lo que deshumaniza con el fin de superarlo. Así, pues, aunque la dirección dominante de este sistema actúe como fetiche y el teólogo haga ver ese carácter y su consecuencia trágica de vivir de víctimas, en definitiva, no puede restringirse a presentar esta característica porque, si se lo trata sólo desde este punto de vista, se lo endurece en vez de ayudarlo a desabsolutizarse y volver a la fluidez de lo histórico.

Devolver el mercado a la fluidez de la historia significa luchar para que vuelva a ser libre, que se reponga la competencia, que se trabaje denodadamente en discriminar positivamente a los que están en desventaja para encaminarse hacia una efectiva igualdad de oportunidades; significa también premiar a la verdadera excelencia, poniendo siempre al descubierto la calidad real de los bienes y servicios, reconduciendo y limitando la propaganda; también implica ir reduciendo el mercado a lo realmente transable, sacando de él los bienes más elementales y compartidos como el aire, el agua dulce, los mares, las selvas y montañas, y aquellos otros bienes que se degradan al convertirlos en mercancía, como el amor, la amistad, la compañía, la vida sexual, la religión. Todo esto implica una tarea ingente, y a la teología le toca hacer ver cómo liberar al mercado de su corporativización y absolutización, y mantenerlo en estado de fluidez y trasparencia, tanto en las reglas de juego como en los bienes y servicios ofertados, es consecuencia del carácter sagrado de la vida y sobre todo de la vida humana, y más aún, de la fraternidad de las hijas e hijos de Dios.

Si se practica consecuentemente, este tipo de teología tiene que pagar un precio muy alto: estar y ser percibida como una fuerza en oposición activa a la dirección dominante. Esta percepción no le hace justicia porque, en el fondo, esta teología busca salvar lo bueno de esta dirección dominante, superando su absolutización o totalitarismo. Pero como los fautores de este sistema se aferran a ese dominio despótico, captan a esta teología como enemigo que hay que neutralizar. Este estatuto hace que no sea bien vista por los que disponen de la opinión ambiental y los medios económicos y políticos, y ni siquiera por gran parte 
de las autoridades eclesiásticas, lo que limita su desarrollo y más aún el estatuto público de los teólogos, para decirlo del modo más eufemísticamente posible.

\subsection{Reponer significativa y creíblemente el horizonte utópico del evangelio}

La teología no puede contentarse con su papel de mostrar el pecado-del-mundo, en nuestro caso, el fetichismo del mercado totalitario, e indicar el camino de su desalienación. Si la teología cristiana está al servicio del evangelio, su tarea primordial en este campo es reponer el horizonte del reino de Dios, decir de manera fehaciente el proyecto de Dios para la humanidad y la creación, revelado definitivamente en Cristo. Sólo si se vive en el horizonte de este proyecto de Dios, se revela la inhumanidad presente. Si se carece de este horizonte, enseguida nos rendiremos a la pretendida evidencia de que así es la vida, y no se verá esta sociedad como fetichista, ni se luchará por denunciar lo inhumano y por cambiarla.

La teología tiene que proclamar, en este mundo que anda patas arriba, lo que es realmente humano, según el parámetro de humanidad, Jesús de Nazaret. Más todavía, tiene que hacer ver que esa humanidad cualitativa es, no sólo sumamente deseable, sino realmente posible, no sólo en abstracto, sino para los seres humanos actuales; y que no sólo es posible, sino que hoy viven entre nosotros seres humanos verdaderamente cualitativos y que son muchos los que se esfuerzan en vivir de este modo, y desde esa vivencia, construir ambientes progresivamente moldeados por esta humanidad y que la retengan y vehiculen.

Tiene que mostrar que la única vida digna del ser humano consiste en caminar en esa dirección ya ahora, sin esperar a que se cambien las reglas de juego y haya unas condiciones más favorables. Este cambio sólo puede provenir de seres humanos que vivan ya alternativamente. La teología tiene que mostrar que sólo así nos encontraremos, nos reconoceremos y daremos lo mejor de nosotros mismos, y superaremos tantas limitaciones y deformaciones, que vuelven la vida una pesadilla o una búsqueda insaciable o una lucha sin cuartel o una frustración.

Esta dirección utópica es irrenunciable para la teología, si se quiere mantener dentro del horizonte evangélico. La mesura, que se niega a imaginar creadoramente posibilidades inéditas, un mundo distinto y una humanidad mejor, es una orientación vital que se resigna al pecado-del-mundo y que se niega a aceptar a Jesús, que es el que nos atrae hacia esas posibilidades humanas con el peso infinito de su humanidad.

Un aspecto irrenunciable de esa utopía evangélica es que los pobres vivan humanamente y que como sujetos dignos, puedan cualificarse cada día más y logren convertir su pobreza en sobriedad elegida, posibilidad de libertad para una convivencia creativa, a la cual se sumen otros de otras clases sociales. Porque, como dice Aparecida, "si no hay esperanza para los pobres, no la habrá para nadie, ni siquiera para los llamados ricos" (395). En esta sociedad terriblemente 
insolidaria, en la que todo tiende a privatizarse, desde la seguridad física a la seguridad social, sociedad llamada eufemísticamente del riesgo, hecha a la medida de los de arriba, que piensan subir hasta el cielo, desligados del lastre de la solidaridad con el común de los mortales, esto todavía suena a necedad, pero dentro de poco revelará su pertinencia.

\section{Papel de la teología en la tercera época latinoamericana}

Desde la dirección dominante de la mundialización no existe América Latina como una realidad cultural con sustancia específica; por el contrario, lo característico de ella es su inadecuación en múltiples aspectos a este mundo globalizado, y por tanto, la desventaja respecto de otras regiones, aunque para los negocios también ofrece evidentes ventajas, sobre todo la minusvaloración de la mano de obra, la menor carga impositiva y una presión menor de la competencia.

Para la teología que se hace desde esta perspectiva, que es la mayoritaria en nuestra región, sobre todo en los centros con acreditación eclesiástica, en buena medida, por la presión central y también, en ocasiones, de los jerarcas locales, lo latinoamericano no tiene ninguna significación especial, salvo, como en las otras áreas, la pobreza de fuentes. Por eso, el material es casi todo foráneo, como el enfoque.

Pero los teólogos que no nos atenemos ni ideológica ni, sobre todo, vitalmente, a la dirección dominante de esta figura histórica, sí vivimos, como los demás que no viven en lo establecido, en América Latina como entidad sociohistórica, dotada de sustancia propia. Por eso, es imprescindible especificar la época que estamos viviendo para ver qué requerimientos nos plantea.

\subsection{América Latina, multiétnica, pluricultural, en justicia e interacción sim- biótica}

Estamos entrando con gran vigor en la tercera época de la región, después de la primera, la amerindia, y la segunda, dominada por los peninsulares y, en definitiva, por los occidentales. Esta segunda época tuvo tres períodos: en el primero, se repartieron el poder los peninsulares europeos y americanos. En el segundo, los americanos echaron a los europeos para mantener ellos solos el señorío sobre indígenas, negros y castas; por eso, las repúblicas salidas de la emancipación fueron repúblicas señoriales. En el tercer período, viendo los europeos que ellos solos no podían hegemonizar a los demás y presionados, además, por el empuje de la población no occidental, consintieron compartir el poder con los de cualquier etnia, con tal de que dejasen su cultura y asumiesen la occidental. Este proceso de modernización occidentalizadora tuvo gran éxito en unos países, aunque no tanto en otros, en los que los prejuicios de casta contuvieron la movilidad, precipitando la crisis de gobernabilidad. 
La tercera época se abre cuando un número creciente de no occidentales se esfuerza por asumir lo más que pueda los bienes civilizatorios y culturales del occidente mundializado, pero no para dejar sus culturas (como había sucedido en el tercer período de la época anterior) sino para que éstas puedan expresarse en el hoy mundializado con toda prestancia. Lo más llamativo de esta irrupción lo han llevado a cabo indígenas del área andina, pero cada vez cobra más fuerza en las demás etnias indígenas, en los descendientes de africanos y en los distintos tipos de mestizos, y a nivel cultural, en gente de cultura campesina y suburbana, que son culturas mestizas, además de las culturas indígenas y la afrolatinoamericana que, como la criolla tradicional y la occidental mundializada, son culturas mestizadas.

Esta tercera época busca que la realidad multiétnica y pluricultural de la región sea plenamente reconocida por todos sus integrantes, en un estado de justicia y de interrelación simbiótica. El resultado de este proceso es que América Latina deje de ser sólo latina y que a nivel institucional y como horizonte compartido sea además indígena, afroamericana, campesina y suburbana. No se desea que este proceso degenere en una desintegración de la región, sino en el reconocimiento (que llegue a nivel constitucional e institucional, además de ideológico y simbólico) de la multietnicidad y la pluriculturalidad por parte de todos, y lleve a la interacción múltiple.

La pujanza de este dinamismo de reconocimiento explica la creciente división que aparece en el seno de cada país. La división ya existía, pero no se manifestaba, mientras los demás aceptaran, en alguna medida, la hegemonía de los occidentales. Es lo que hoy sucede cada vez menos. Sin ese telón de fondo no es posible comprender ni valorar adecuadamente la victoria de Evo Morales, en Bolivia, la de Correa, en Ecuador, la de López Obrador, en México (que no fue reconocida), la de Lula, en la segunda vuelta (cuando habló este lenguaje), en Brasil, la de Chávez, en Venezuela, la casi victoria de Humala, en Perú, y tal vez la de Kirchner, en Argentina.

\subsection{El paradigma de pentecostés frente al paradigma reinante de babel}

¿Cómo es la teología de los teólogos que entran decididamente en esta tercera época, cuando lo hacen llevados no por una emoción populista, sino por un discernimiento cristiano? La primera función de la teología es hacer ver el dinamismo del Espíritu en esta lucha, porque todas las culturas se reconozcan, se respeten, se expresen a todos los niveles de la existencia privada y pública, y cambien la dirección de prevalecer por la de dialogar e intercambiarse simbióticamente. Este intercambio ha de darse ya en el proceso: es la ayuda de personas de cualquier cultura para que se reconozcan los derechos de las no reconocidas hasta hoy. Este luchar codo con codo, sin sustituir a nadie, sino apoyándose como distintos e iguales, es lo único que puede dar como resultado, no un mosaico de culturas, sino una sola región multiétnica y pluricultural. 
Que el Espíritu mueva en esa dirección no significa sacralizar ninguna cultura. Ninguna cultura es cristiana, porque en ninguna cabe el ser humano a la medida de Cristo, pero todas son camino adecuado para transitar en esa dirección, trasformando desde dentro cada cultura. En ese caminar conjunto nos reconocemos y apoyamos.

El dinamismo histórico de las culturas y el no sacralizar a ninguna impide considerar a ninguna en conjunto y a ningún rasgo de ellas como paradigma absoluto. Las culturas son para que, transitándolas, las personas lleguen a constituirse en cualitativamente humanas, según el paradigma absoluto de humanidad, que no cabe en ninguna. Por eso, al valorar las culturas preteridas, hay que evitar que ocurra como con la criolla tradicional y ahora con la occidental mundializada que, por absolutizarse, dificultan enormemente que sus miembros las trasciendan, ya que según sus líderes, ellas son la expresión humana cabal o el marco adecuado para serlo, según los modelos propuestos.

\subsection{El paradigma del mediador, de raigambre cristológica}

Por lo que se ve, este cambio de época no va a ser fácil, ni concertado y pacífico. El teólogo, a nivel formal y como miembro de la academia, y no pocas veces por origen familiar $\mathrm{y}$, en todo caso, por estatus profesional, pertenece al occidente americano o, incluso, se siente un miembro periférico de la teología occidental. Eso significa que tenderá a ver los movimientos para vencer las resistencias de los occidentales privilegiados, que no quieren relativizarse, como ruptura del orden, como fin de un mundo para él lleno de sentido, a pesar de todo, con el cual se identifica. Tenderá a verlos como movimientos que le quitan el piso y le destruyen la casa y lo dejan a la intemperie. Se sentirá emocionalmente desafecto a ellos, los verá, aunque no se lo diga ni a sí mismo, como los bárbaros invasores, que están acabando con las ciudades esplendorosas, con las instituciones, con las costumbres, con un orden que costó siglos levantar.

Sin una vigorosa vida teologal, el teólogo será incapaz de trascender esta posición vital, y su teología será incapaz de discernir por dónde pasa hoy, en América Latina, el Espíritu del Mesías pobre de los pobres. Su teología, tal vez muy erudita, será, sin embargo, ciega para lo esencial, que es el paso de Dios, en la historia que lo implica, y no podrá ayudar a mantenerse cristianos a los que vienen, porque no les mostrará el evangelio de que Dios está con ellos y, por eso, les pide que lleven a cabo esta tarea, que él quiere, con el Espíritu de Dios y no con el de revancha. Tampoco podrá ayudar a los occidentales a reconocer y ocupar su puesto.

El teólogo está llamado a deponer prejuicios, a salir de la querencia y lanzarse al viento de la historia, dejando el puerto nativo, a vivir sin tocar fondo, ni ver ningún puerto; está llamado a vivir sin señales que le den seguridad, para que en altamar se abra por fin a los que vienen abriendo la historia, y sea capaz de descifrar los signos de los tiempos, como pide su Maestro. Si se abre a los 
otros, será capaz de ver cómo actúa el Espíritu de su Señor en ellos y podrá servir a su justa causa. Será un mediador entre su mundo nativo, del cual salió, y el cual pugna por construirse.

Desde esta posición vital, será capaz de presentar a Jesús de Nazaret como mediador entre Dios y los seres humanos y entre los seres humanos entre sí. Será capaz también de presentar la figura humana del mediador como el sujeto humano que hará posible que se encuentren en nuestra América, todas las sangres y surja por fin el tiempo nuevo: una América multiétnica y pluricultural, en estado de justicia e interacción simbiótica. Esta fue la propuesta de Pablo: en Cristo, decía, no hay libre ni esclavo, griego ni bárbaro, judío ni gentil, varón ni mujer. No quería anunciar una humanidad homogénea, que es el paradigma de Babel, sino que estas diferencias no serían ya motivo de discriminación, sino de enriquecimiento al interactuar en un estado de justicia y mutuo reconocimiento.

\section{Papel de la teología en el mundo actual}

El mundo actual, a nivel religioso, se caracteriza, tanto por el relegamiento de lo religioso al ámbito privado como por el auge de los fundamentalismos. El primer fenómeno, característico del occidente y sus áreas de influencia, proviene de dos factores: el predominio de la razón crítica y la razón instrumental científico-técnica, y la necesidad de encontrar bases contractuales de convivencia para superar el impasse que crearon las distintas confesiones cristianas, que pretendían que la sociedad se estructurase desde su hegemonía.

El fundamentalismo tiene una doble raíz: en los configurados por el sistema, compensar la falta de sentido y la banalización de la existencia, que provoca la absolutización del circuito producción-consumo; en los excluidos del sistema y amenazados frontalmente por él (el caso más significativo es la cultura islámica), es el modo más expedito de resistir a su embate para no verse privados de sustancia humana y consistencia cultural, cuyo pivote es la religión.

\subsection{Reivindicar la autonomía de la conciencia y la sana secularidad, frente al totalitarismo de mercado y los fundamentalismos}

La autonomía de la conciencia y la sana secularidad fueron reconocidas por el Vaticano II como algo querido por Dios; pero hoy, tienden a ser restringidas progresivamente $\mathrm{y}$, en el fondo, negadas por las corrientes neoconservadoras y fundamentalistas. Hoy, en la práctica, se vuelve a la lógica de que el error no tiene derechos, para concluir que tampoco los tiene el que yerra, que es lo que se quiere decir en el fondo, ya que sólo los seres humanos son sujetos de derechos y no los enunciados.

En el Vaticano II, se pasó de entender la revelación como la manifestación por Dios de enunciados que caen más allá de la posibilidad humana de llegar a 
ellos, a comprenderla como la autorrevelación de Dios, entendida como comunicación libre y amorosa de sí y, en el fondo, como donación de sí mismo. Sólo una conciencia que es capaz de percibir y recibir esa autocomunicación y de responder libremente a ella desde lo más profundo de su ser, es correlato digno de este designio de Dios.

Esa conciencia autónoma es también el sujeto adecuado de una vida social y política, acorde con el designio de Dios. Ella excluye, pues, la sociedad estamental y corporativa (basada en privilegios étnicos, hereditarios o económicos) $y$, por ende, el modelo de la Iglesia como estamento privilegiado.

Hay que afirmar, empero, que la libertad de conciencia nada tiene que ver con la propuesta ambiental de hacer lo que a cada uno le venga en gana, que equivale a dejarse llevar por la corriente en cualquiera de sus vertientes. Obrar por impulsos autonomizados, que no responden al fondo del corazón, desde donde se decide la vida en su autenticidad, es obrar desde el servo arbitrio (un albedrío sometido), que decía Lutero, y no desde una libertad liberada. Ahora bien, tampoco lo es la heteronomía consecuente y consentida, que se entrega a una ley sacralizada, y en el fondo, a sus representantes, que participan de hecho de su misma absolutez, tal como proponen, y en el fondo imponen, los fundamentalismos en boga. En definitiva, es la conciencia la que tiene que decidir, y nada ni nadie puede ahorrarle este trabajo, ni este riesgo, ni presionarla en ninguna dirección.

El teólogo debe proseguir su tarea de sistematizar y fundamentar esta visión que alcanzó tardíamente el Vaticano II y dista de estar asumida por el grueso de los católicos y, menos aún, por los personeros de la institución eclesiástica. La urgencia de esta tarea es no sólo la misión que tiene la teología de actualizar la tradición, y en este caso se trata del núcleo antropológico de ella, ya que Cristo nos liberó para ser libres y, por tanto, tenemos que mantenernos firmes para no recaer bajo el yugo de la esclavitud (Gal 5, 1), sino también las formidables amenazas actuales, ya que las corporaciones mundializadas y los grupos étnicos y religiosos corporativizados tienden a recortar drásticamente la autonomía de la conciencia. También esta tendencia se apodera cada vez más de las instancias de decisión de la Iglesia católica. Éste es un punto en que el teólogo tiene que ver claro y liberar su libertad para manifestarlo cargando con el precio.

\subsection{Discernir el proceso histórico para superar sacralizaciones indebidas sin caer en la banalización de la existencia}

Más arduo se presenta el panorama del predomino de la razón crítica e instrumental. El teólogo tiene que comprender las causas de la pertinencia histórica de la aplicación a fondo de este uso de la razón. En nombre de la revelación, cuyo depósito pretendían custodiar, las jerarquías de las diversas confesiones cristianas se absolutizaron, negaron de hecho la posesión del Espíritu y la capacidad de juzgar a los cristianos, y se arrogaron una verdadera dictadura sobre las 
conciencias, que no se restringía únicamente al fuero interno, sino que se apoyaba en el brazo secular para privar de libertad, de bienes y cargos e incluso de la vida a los disidentes. Por su parte, el poder político, que también se estaba absolutizando, aprovechó la alianza con la institución eclesiástica para sacralizarse.

En estas condiciones (que se fueron imponiendo a medida que avanzaba el siglo XVI y prevalecieron en le siglo XVII) fue providencial que personas sensatas relativizaran (sobre todo en la segunda mitad del siglo XVIII) una sacralización que había producido frutos tan envenenados y que había llevado a Europa a un callejón sin salida. Dios no puede apoyar las tiranías políticas y religiosas, y privar de la capacidad de pensar y decidir a las personas. Esa imagen de Dios, decían, no puede ser la del Dios verdadero. Y prefirieron buscarlo en los que consideraron los verdaderos santuarios: la naturaleza y la conciencia. Así, sobre todo, Rousseau y Kant.

Ésta que llamaron religión natural, frente a tanto sobrenaturalismo asfixiante, fue una reacción que podemos considerar saludable: un proceso necesario de desintoxicación.

Al llevar el desmonte crítico no sólo a las actuaciones de los eclesiásticos y a las instituciones históricas (así lo reconoce el teólogo Ratzinger, Benedicto XVI, en su reciente Jesús de Nazaret, Bogotá 2007, también 64-65), sino también a la capacidad del ser humano de asir la realidad, tanto la propia como la del mundo y la historia y, por supuesto, la de Dios, pasaron de la necesaria tolerancia al relativismo, al agnosticismo y, finalmente, al indiferentismo y a la banalización de la existencia. De la fuerte exigencia ética de los primeros se pasó al pragmatismo y de ahí al darwinismo social.

\subsection{La pertinencia del tránsito del empirismo a la realidad y al misterio}

Este desmonte de cualquier pretensión metafísica, en el sentido de posibilidad de llegar a la realidad, fue posibilitado por la combinación de la razón crítica con la instrumental, que sustituyó a la metafísica. Se declaró que lo no sometido a cuantificación era sólo una opinión o una convicción, no una realidad comprobada. De este modo, las únicas ciencias eran las físico-matemáticas, entendidas desde el rígido paradigma newtoniano; ellas constituían el único paradigma respetable.

Desde esa perspectiva, la religión era sólo asunto de convicciones individuales o grupales; en todo caso, asunto privado, absolutamente prescindible, a la hora de organizar la existencia social y de esbozar proyectos históricos motivadores.

En este punto, la teología tiene la muy ardua labor de mostrar la posibilidad de que el sujeto trascienda su enclaustramiento en sí y pueda ser afectado por la realidad y percibirla, y, más aún, que pueda percibir su originaria posición en la realidad que lo constituye como humano y lo diferencia de los animales (el ser humano como animal de realidades), incluso su ser fundamentado en ella y posibilitado por ella. 
Más aún, tiene que mostrar más particularmente cómo el dinamismo humano desborda la mesura de la finitud y puede sortear, por otro lado, la mala infinitud proyectiva y situarse ante el misterio, aunque sea captado como silencio, vacío o exterioridad no totalizable. Creemos que el nuevo paradigma científico no sólo es compatible con esta operación, sino que es buen conductor, por así decirlo, de ella.

\subsection{No escamotear que el cristianismo ha dejado de trasmitirse ambiental- mente}

De todos modos, queda el hecho de que cada vez en más ámbitos, incluso en América Latina y, más recientemente, en ciudades modernas de África y Asia, el cristianismo ha dejado de trasmitirse ambientalmente. Esta externidad del cristianismo respecto de la cultura ambiental mundializada ha llegado al punto de que un creciente número de contemporáneos occidentales no es capaz de descifrar el lenguaje del arte cristiano, que colma las ciudades antiguas; incluso el calendario civil, que aún continúa estructurándose en parte en torno a festividades litúrgicas, sobre todo los ciclos de Navidad y Semana Santa, está perdiendo rápidamente las referencias a la vida de Jesús, que las originaron.

Hay quienes piensan que el catolicismo popular sigue siendo una fuerza activa con la que el pueblo se evangeliza a sí mismo, para tomar la expresión de Puebla. Creemos que esto es así únicamente en aquellas personas que lo viven de manera personalizadora, es decir, en quienes lo han tomado en sus manos y lo actúan y lo moldean desde su situación. Gracias a Dios, todavía se dan estas personas; pero son un grupo minoritario, que no es capaz de impregnar su ambiente y su cultura, aunque los de su entorno todavía los reconocen como personas dotadas de autoridad, porque dan vida y crean y trasmiten sentido.

Un descubrimiento de estas décadas es que lo ritual es lo último que sobrevive, cuando ya el cristianismo ha dejado de servir para dirigir la vida cotidiana y para orientar las instituciones y la política. No poca gente, por lo demás muy secularizada, quiere de corazón que los eventos más trascendentes de su vida y de su grupo tengan una expresión ritual, que exprese la hondura que tiene la existencia humana, y al expresarla religue de algún modo con ella por esta vía, ya que el acceso parece estar negado en la cotidianidad, por la manera como está organizada la sociedad. En este espacio-tiempo, las personas están dispuestas a escuchar una palabra significativa y a sumergirse en una celebración que, por su calidad, evoque realmente la trascendencia.

Están naciendo y estructurándose liturgias seculares, que sustituyen a las católicas. Pero mucha gente que no se ha dejado moldear completamente por la dirección dominante de esta figura histórica, sigue prefiriendo los ritos religiosos porque los laicos no son verdaderos ritos, sino meras ceremonias carentes de profundidad, por más pomposas que sean. 
Es un reto teológico valorar esta ritualidad, una dimensión bastante ausente de la teología moderna ilustrada, como lo era también de la teología tridentina, demasiado atenida a lo doctrinal y jurídico.

Esta demanda ritual hace creer equivocadamente a gran parte de la institución eclesiástica establecida que todavía está vivo el catolicismo ambiental y que su oferta tiene sentido, cuando, por una parte, es el canto del cisne de la vivencia religiosa y, por otra, la demanda se siente por lo general bastante frustrada por la oferta eclesiástica.

\subsection{Proponer la reconversión institucional de la Iglesia}

Sería muy triste que en América Latina se diera la descristianización de Europa. No sería malo sólo para la Iglesia, sino también y más aún para América Latina. Pero para que no se dé, se requiere que la institución eclesiástica deje de pensarse como representante de la sociedad, apoyándose en el número de los bautizados, y que, desde la libertad que da el no pretender ostentar, ni ejercer el poder, se atenga a su misión evangelizadora.

En nuestro continente, fuera de algunas élites, no hay anticlericalismo. En la época republicana, se dio la lucha entre el poder nuevo de las élites criollas y el poder consolidado de la Iglesia, que resistió incólume el paso de la emancipación. A la institución eclesiástica le costó mucho aceptar que no estaba ya ante un Estado que se profesaba misional, y que tenía que aceptar como un bien para ella y el cristianismo la secularización del Estado y la falta de apoyo del brazo secular, y que esta despolitización la liberaba, para que su referencia fundamental fueran las personas y la sociedad, lo público no estatal, y no el Estado.

Actualmente, dejar la referencia fundamental, aunque subrepticia al Estado y actuar en este campo por medio de los cristianos, y no como élites con peso político, daría a la institución eclesiástica la libertad que precisa para poner todas sus energías en la evangelización, una evangelización fundante, como respuesta a la falta de trasmisión ambiental.

No es mucho lo que la teología puede hacer para que la institución eclesiástica efectúe decididamente este giro, pero deberá hacer todo lo que esté en su mano. El punto de partida es evidenciar que una Iglesia particular no puede dar por asentado que posee realmente el evangelio de Jesucristo, puesto que ello no equivale a tener la Palabra de Dios y los sacramentos, sino que implica que, de hecho, contempla diariamente la Palabra y se constituye en comunidad, que la escucha discipularmente, la vive en los diversos niveles de la existencia y la celebra en los sacramentos. Por eso, antes de emprender el proceso de evangelización es precisa una reevangelización interna.

Si no se da esta reevangelización que entrañe una verdadera conversión, la tentación que acecha es diseñar misiones con la ayuda técnica de expertos en 
mercadeo, que propongan campañas para recuperar el mercado perdido y, si es posible, incursionar sobre nuevos adeptos. Este tipo de campañas degrada el evangelio a un producto que se debe presentar como atractivo, independientemente de su propia lógica y sus contenidos, ligándolo a deseos primordiales, como se hace con los demás productos. Esta falta de fe en la virtualidad del evangelio vacía a sus promotores de trascendencia y significatividad. Por este medio, se hace despreciable el evangelio.

Pretender recuperar significatividad con técnicas, para tapar la falta de densidad cristiana y no pagar el precio de la conversión, es una tentación muy grave que la teología debe desenmascarar. Pero, como hemos insistido a propósito de la entraña fetichista del mercado totalitario, también en este punto es preciso que la teología pueda proponer convincentemente a la institución eclesiástica el evangelio de Jesús de Nazaret, de tal manera que lo perciba como un tesoro por el que bien vale la pena darlo todo.

\subsection{Relación entre el no reconocimiento de Dios y la entrega envilecedora a las obras de nuestras manos}

Aunque no dudamos de que pueda existir y exista una secularidad atenida a la mesura de lo finito, que se empeñe en poner de relieve y vivir aspectos medularmente humanos y en luchar para que todos tengan tendencialmente oportunidades para vivirlos, tampoco dudamos en afirmar que, de hecho, en nuestras sociedades se da una correlación entre el no reconocimiento y la falta de vivencia de la religación primordial a Dios, y la entrega a la sociedad de bienestar como un horizonte que empequeñece, vacía de densidad humana y anestesia respecto de la injusticia masiva y brutal, que se ejerce estructuralmente.

La teología deberá poner de relieve la correlación entre el no reconocimiento del Dios vivo y verdadero y la entrega a las obras de nuestras manos y la fetichización de las reglas de juego, donde se afinca la dirección dominante de esta figura histórica. En teoría, no es concluyente que, como decía un personaje de Dostoievski, si Dios no existe, todo está permitido. Pero en nuestra historia, tomando los grandes números, ha sucedido así. Y no por casualidad, sino porque, si la relación gratuitamente creativa de Dios con el ser humano lo hace real, el no reconocimiento de esta relación lleva consigo el falseamiento de nuestra peculiar realidad: el ansia incurable del que se aprehende como un mero hecho sin fundamento, y la búsqueda de sucedáneos, sea uno mismo o alguna institución o persona a las que atribuimos el poder de fundarnos. Si ignoramos la relación de amor que nos funda, las relaciones serán vistas como algo secundario y el individuo aparecerá como una mónada, que deberá conquistar la mayor densidad posible y vivir para sí mismo.

El teólogo tiene que convencerse de que hablar convincentemente de Dios es un servicio insigne, que puede y debe prestar a sus contemporáneos, y que no hacerlo, es contribuir a que la sociedad sea más inhumana y el ser humano más 
vacío. Pero no podrá convencerse, ni llevarlo a cabo fehacientemente, si no vive una vida teologal. Desde lo que llevamos dicho, no cabe duda de que éste es el desafío primordial del teólogo y el punto de partida y la condición de posibilidad de su teología.

\section{Fundamentar la mutua implicación entre Jesucristo y los pobres}

Para concluir, y como condensación recapituladora de todo lo dicho sobre el papel de la teología, queremos glosar una frase, que hemos citado de Aparecida, una frase realmente sistemática, que nos lleva a las entrañas de la originalidad del cristianismo, respecto de las demás religiones y, por tanto, de su misión en el mundo actual. La frase es tan significativa que, aunque esta asamblea no hubiera dado ningún otro aporte, se justificaría, por haberla proferido con su autoridad. Dice así: "Todo lo que tenga que ver con Cristo, tiene que ver con los pobres y todo lo relacionado con los pobres reclama a Jesucristo" (257). La frase une dos realidades heterogéneas: una realidad personal, que tiene además una singular densidad religiosa, Jesús, Hijo único de Dios, y una realidad social, un colectivo histórico, que en sociología se califica negativamente: los que no tienen, más aún, los que no tienen cómo tener. La sentencia une lo que tiene más densidad con lo que aparece como lo que menos densidad tiene. Y los une en una implicación recíproca total: lo que tiene que ver con Jesús, tiene que ver con los pobres, y lo que tiene que ver con los pobres tiene que ver con Jesús.

Esto mismo se dice en el evangelio de la relación entre Jesús y el Padre. Decirlo de Jesús y los pobres suena a una sacralización indebida de los pobres. Suena escandaloso, como si fuera una blasfemia, si no podemos asumirlo, como no es posible en este caso, como una necedad. Creemos que una teología desde el tercer mundo, más aún, una teología precisamente desde América Latina, la única región del tercer mundo con mayoría cristiana y en donde el cristianismo más cualitativo y mayoritario se da entre los pobres, tiene como función fundamentar y desentrañar de forma sistemática esa mutua implicación, tan hermosamente expresada en esta sentencia, que es una verdadera tesis, de Aparecida.

\subsection{La singularidad y trascendencia de la encarnación y su carácter kenótico}

Daremos tan sólo algunas pinceladas. Hay que partir del hecho, desconocido por las demás religiones, de la encarnación. Este acontecimiento no tiene cabida ni en el judaísmo (por eso, fueron expulsados los judeocristianos de las sinagogas), ni en el islamismo. Menos aún, en el budismo, que en su versión más primigenia, no es temáticamente religioso. Los avatares del hinduismo son personificaciones funcionales, que se parecerían al concepto de persona de la Grecia clásica, que designa la caracterización de un personaje en una representación, que para ellos era algo sagrado, que desvelaba los misterios de la existencia y ayudaba a vivirlos dignamente. Ninguna religión incluye, como pieza central, el 
acontecimiento de que un Dios se haga eternamente un ser humano, que forme parte de la humanidad, de tal manera que corra su suerte.

Este acontecimiento es tan único que incluso a los católicos les cuesta pensarlo y más todavía hacerse cargo de él, y por eso, una y otra vez, surgen dos desviaciones. Una, la más extendida entre los católicos practicantes, sostiene que Jesús se vistió de la naturaleza humana, pero que por debajo de esta apariencia, era el mismo Dios que antes. Jesús desde su nacimiento todo lo podía y todo lo sabía. No caben en él las limitaciones humanas. La otra desviación es típica de intelectuales, también de teólogos, entre ellos muchos actuales, y sostiene que Jesús es hijo de Dios como lo somos todos nosotros, sólo que lo vivió de una manera enteramente excepcional, es decir, con una conciencia total de lo que eso implicaba y, por tanto, con entera consecuencia; por eso, nos alumbra el camino para llegar nosotros a serlo con la misma autenticidad.

Pues bien, nosotros sostenemos lo que hemos recibido: Jesús es el Hijo único de Dios que se ha hecho uno de los seres humanos. Si creer esto es un don de Dios, mucho más lo es creer y aceptar con admiración, agradecimiento y alegría, que Jesús se hizo un ser humano pobre y que cuando se lanzó a la misión, dejó la precaria instalación, es decir, la familia y el oficio, y se hizo un judío marginal, que no sólo no tenía dónde reclinar la cabeza, sino que carecía de identidad social.

Ahora bien, el que Jesús formara parte del colectivo de los pobres no implica de suyo que estuviera ligado a ellos, como afirma nuestro axioma. Pero en el caso de Jesús sí lo implica, porque su inserción en ese mundo fue elegida por su Padre y libremente aceptada por él. Si el envío del Espíritu para habilitar a María fue una decisión soberana de Dios (eso significa precisamente la representación de la Anunciación), el que Jesús naciera en una familia que no tenía dinero para comprar un cordero para purificar a la madre y se limitara a dar dos pichones, expresa la solidaridad de Dios con el colectivo de los pobres. Por eso, a ellos se anuncia su nacimiento como una buena noticia, que los llenará de alegría.

\subsection{Mutua implicación entre la vida de Jesús y su doctrina, y los pobres}

Por eso, en el discurso programático que pone Lucas sobre la misión de Jesús, escoge el texto que anuncia que Dios lo ha ungido con su Espíritu para dar a los pobres la buena nueva de su liberación; y las señales que da a los enviados del Bautista para que reconozca en él al profeta escatológico son el anuncio del evangelio a los pobres y el dar la plenitud de vida a los que la tenían disminuida. Por eso, el discurso que explana su mensaje se abre con la proclamación a los pobres de que son felices, porque el reinado de Dios es para ellos. Y no sólo es para ellos esa entrega absoluta e irrevocable que Dios hace de sí, en el mismo momento que se proclama, también serán ellos los que se sentarán en el banquete eterno del reino. Esta entrega actual de Dios a los pobres y esa promesa escatológica son creíbles por ellos, porque el propio Jesús las sacramentalizaba con 
la entrega ilimitada de sí. Los pobres supieron que Jesús era suyo, que podían disponer de él.

Muchos pobres aceptaron esa entrega, y se entregaron a su vez a Jesús, de tal manera que eran realmente los suyos. La prueba más elocuente de que Jesús era su dirigente es que en la fiesta de la pascua lo seguían con tal fervor que las autoridades, asustadas por esa ingente movilización y más todavía resentidas al ver que todo el mundo se iba tras él, decidieron quitarlo del medio. Pero decidieron hacerlo después de la fiesta, porque la gente formaba un verdadero escudo a su alrededor. Y cuando lo apresaron de noche, por la traición de un discípulo, y lo sacaban a crucificar, los peregrinos que entraban a Jerusalén lo acompañaron solidariamente, y después de la ejecución, se volvieron dándose golpes de pecho, como aún hoy hacen los semitas, en señal de rabia y protesta.

Es cierto, pues, que en la vida de Jesús se dio, de hecho, esta mutua implicación. Ella no fue una mera eventualidad, sino un acontecimiento revelador tal como se confirma con su doctrina, cuyos rasgos más salientes hemos apuntado. Por eso, tiene la categoría de tesis sistemática, como asentamos.

Ahora bien, para asentar su carácter sistemático, tenemos que hacer ver que los pobres entran en las otras relaciones que caracterizan a Jesús y a su misión.

\subsection{Mostrar en la misión de Jesús la triple implicación: entre pobres y to- dos, pobres y pecadores, pobres y Dios}

En primer lugar, habría que hacer ver cómo los pobres están referidos al conjunto de la humanidad, porque no cabe duda de que Jesús ha sido enviado por Dios para salvar a todo el género humano. Es cierto que la voluntad universal de salvación es un dato primigenio de la revelación cristiana ¿Cómo se relaciona con la implicación entre Jesús y los pobres? Los pobres son camino absoluto de salvación universal. Eso es lo que expresa esta frase de Aparecida: "si no hay esperanza para los pobres, no la habrá para nadie, ni siquiera para los llamados ricos" (395). Cuando a los pobres les vaya bien, les irá bien a todos, y no les irá bien en ninguna otra hipótesis. Sólo colaborando a humanizar la pobreza, de manera que los pobres puedan convertirse en sujetos de la superación de la pobreza, sólo en esta colaboración fraterna, pueden humanizarse los no pobres. No hay una humanización que prescinda de la ayuda a los pobres. Ni siquiera la religión que prescinda de los pobres o los contemple tangencialmente puede lograrlo. Esto se aplica también, obviamente, a los propios pobres, para los que optar por ellos les resulta tanto o más difícil que a los demás.

Jesús ha venido también a salvar a los pecadores. ¿Tiene que ver algo la salvación de los pecadores y los pobres? Eran tenidos como pecadores en la cultura judía los que vivían de tal modo que se entendía que despreciaban o violaban sistemáticamente la ley de Dios, que se consideraba como fundamento de la 
sociedad. Por eso, con su conducta socavaban el orden social y los guardianes del orden los repudiaban como antisociales. Para ellos, los pecadores por excelencia eran los recaudadores de impuestos, porque esquilmaban al pueblo para enriquecer a los romanos o a Herodes, que estaba subordinado a ellos. Había en esto una gran hipocresía, porque los fariseos y, en general, los maestros de la ley transigían con los romanos, a cambio de que les permitieran vivir conforme a la Torá y desviaban la odiosidad de este pacto hacia los encargados de recaudarlos. Estas personas resentían el desprecio y el aislamiento, y por eso, aceptaron primero la invitación a convertirse del Bautista y luego el que Jesús los acogiera de corazón, sin juzgarlos. El resultado de la cercanía de Jesús les daba la esperanza de que Dios no los había desahuciado, como les habían hecho creer sus autoridades. La consecuencia está muy bien ejemplificada en la escena del banquete que ofrece Zaqueo: da a los pobres la mitad de su fortuna. Es importante hacer notar que la conducta de Jesús no es una estrategia para ablandar a los pecadores. Él los acoge incondicionalmente, y precisamente, esa gratuidad del hombre de Dios, es la que provoca el cambio, que se traduce en generosidad gratuita, y no tampoco para comprar la salvación. Así, pues, el pecador genuinamente convertido se vuelca sobre el pobre, humilde y agradecidamente, sin apabullarlo.

Los otros pecadores públicos, la mayoría, eran muchos pobres que al no poder vivir en la normalidad, es decir, dentro del establecimiento, aunque fuera en los puestos inferiores, no tenían ni tiempo ni atención ni demasiado interés en cumplir tantos requisitos, o eran también los que, por su oficio, no podían o se les hacía demasiado cuesta arriba hacerlo, por ejemplo, los pastores o sencillamente los que estaban demasiado absorbidos por la labor de subsistir y ni siquiera conocían la ley. A ésos se refiere el jefe del templo al decir que los que seguían a Jesús eran "esos malditos que no conocen la ley (Jn 7, 49). En este caso, es obvio que pobres y pecadores coinciden.

La tercera referencia de Jesús, la más absoluta, es a su Padre. No vamos a explayar cómo se implican Dios y los pobres, porque al hablar de la doctrina de Jesús ya lo hemos hecho. También podíamos citar los pasajes más centrales del Antiguo Testamento. Para nuestro propósito, baste con decir que un Dios que se alía con los pobres y se revela ya en ellos, no es ni proyección de las jerarquías sociales, ni opio del pueblo, es decir, que la implicación entre el Dios de Jesús y los pobres es la mayor garantía de la trascendencia de ese Dios. Por eso, ha sido tan poco practicada en todas las religiones, incluida la cristiana. No hace falta decir que un Dios implicado con los pobres no es el Dios de los dioses, ni el Señor de los señores, no es el que corona las jerarquías sociales trascendiéndolas. Tampoco es el consuelo que el pueblo se da de su postración actual, resignándose a ella con la esperanza de que en la otra vida se va a invertir la suerte. No lo es porque no se remite a la otra vida: el reinado de Dios en ellos es actual y, por eso, son felices ya, si se abren a esa relación que los dignifica y moviliza, como pasó a través de Jesús. 
Después de estos apuntes, no dudamos en afirmar que el teólogo que viva como intelectual orgánico de la Iglesia de los pobres, que es el núcleo generador de la Iglesia, es decir, su corazón, tiene encomendado, como parte esencial de su papel, fundamentar y desarrollar sistemáticamente el axioma de Aparecida: "Todo lo que tenga que ver con Cristo, tiene que ver con los pobres y todo lo relacionado con los pobres reclama a Jesucristo". 